\title{
A systematic literature review to compare quality of life in psoriasis with other chronic diseases using EQ-5D-derived utility values
}

This article was published in the following Dove Press journal:

Patient Related Outcome Measures

7 July 2015

Number of times this article has been viewed

\author{
Anders Holmen Møller' \\ Sandra Erntoft ${ }^{1}$ \\ Gabrielle R Vinding ${ }^{2}$ \\ Gregor BE Jemec ${ }^{2}$ \\ 'LEO Pharma A/S, Ballerup, Denmark; \\ 2Department of Dermatology, \\ Roskilde Hospital, Health Sciences \\ Faculty, University of Copenhagen, \\ Copenhagen, Denmark
}

Background: Psoriasis is a chronic, immune-mediated dermatological disease associated with substantial economic, clinical, and humanistic burden.

Objective: The aim of this study was to understand the disutility of patients with psoriasis vulgaris, using mean baseline EuroQoL five dimensions (EQ-5D) index scores reported in the published literature, and to compare this to patients with other chronic diseases.

Methods: Two systematic literature searches were conducted according to the Preferred Reporting Items for Systematic reviews and Meta-Analyses (PRISMA) guidelines. Searches were conducted in ten databases including Embase, MEDLINE, and the Cochrane Central Register of Controlled Trials (CENTRAL). The first search (December 2013) used search terms psoria* AND (EQ5D OR EQ OR EUROQoL). Only publications of original research, which reported baseline EQ-5D scores for mild/moderate/severe psoriasis, were included. The second search (March 2014) used the terms (systematic review) AND (EQ5D OR EQ 5D OR EuroQoL). Titles were screened by two independent reviewers. Four independent reviewers reviewed titles and full-length papers. EQ-5D scores for psoriasis patients were qualitatively compared with scores from patients with other chronic diseases identified through the literature search.

Results: Of 133 publications on psoriasis, 12 met the inclusion criteria. The mean EQ-5D index scores for psoriasis (all severities) ranged from 0.52 (standard deviation: 0.39 ) to 0.9 (standard deviation: 0.1 ). Of the 48 results from the second search, six met the inclusion criteria. The reported EQ-5D lower limit for other diseases ranged from 0.20 (Type 2 diabetes mellitus) to 0.66 (liver diseases). The highest EQ-5D estimates for other diseases ranged from 0.79 (liver diseases) to 0.93 (cancer patients). Both lower and upper EQ-5D estimates in psoriasis patients were within the range of those reported for other chronic diseases.

Conclusion: Comparative studies of morbidity are relevant in health care studies and patient advocacy. This systematic review demonstrates that the ranges of disutility among psoriasis patients are within the ranges of other chronic diseases (cardiovascular diseases, diabetes, endstage renal diseases, liver diseases, cancer, and visual disorders).

Keywords: dermatology, HRQoL, humanistic burden, disutility, EuroQoL

\section{Introduction}

Psoriasis is a chronic, immune-mediated dermatological disease with an estimated prevalence ranging between $0.91-8.5 \%$ worldwide. ${ }^{1}$ It is estimated that half of psoriasis patients $(52 \%)$ have a mild form of the disease $(<2 \%$ body surface area [BSA] coverage), $36 \%$ have moderate disease (3\%-10\% BSA), and 12\% have severe disease ( $>10 \%$ BSA) (based on United Kingdom data). ${ }^{2}$ Symptoms (including itching, scales, and redness) can be alleviated by appropriate treatment, but no cure exists. ${ }^{3}$
Correspondence: Anders Holmen Møller LEO Pharma A/S, 55 Industriparken, 2750 Ballerup, Denmark

Tel +45 44945888

Email anders.moeller@leo-pharma.com 
Psoriasis vulgaris (chronic plaque psoriasis) is the most common subtype of psoriasis, accounting for $90 \%$ of all cases. ${ }^{4}$ It presents on the skin as erythematous, silvery scaled papules, or plaques. ${ }^{5}$ Although primarily a skin disease, psoriasis is associated with significant physical and psychological comorbidities including psoriatic arthritis, cardiovascular disease, and depression. ${ }^{4,6}$

Due to the immediate visibility of the disease, psoriasis can lead to considerable psychological stress and psychosocial disability, with acute feelings of stigmatization. Psoriasis reduces the self-esteem and emotional well-being of patients and can adversely affect social activities and intimate relationships. ${ }^{5,7}$ In a survey of UK psoriasis patients, nearly three quarters reported that psoriasis limits their social activities, half reported that it causes them to cancel social engagements, and one-third suggested that the condition made it difficult to make new friends. ${ }^{8}$

Depression is recognized as a significant comorbidity related to psoriasis, with one study reporting that $46 \%$ of the psoriasis population had higher depression scores than individuals with psychiatric problems. ${ }^{9}$ Another study found that $5.5 \%$ of psoriasis patients reported active suicidal ideations. ${ }^{10}$ Furthermore, the physical complications of psoriasis (including itching, joint inflammation, and pain) can lead to difficulties in performing activities of daily living such as climbing stairs, housework, and bathing. ${ }^{3}$ Although the physical, social, and psychological difficulties linked to the condition are well reported, the resulting burden to patients' overall health-related quality of life (HRQoL) is underestimated. ${ }^{10}$ In spite of the immediate visibility of skin diseases, physicians' and patients' assessment of the impact on HRQoL does not always correlate. ${ }^{11}$ Several dermatology/ psoriasis-specific tools have been used to investigate HRQoL in psoriasis patients. While there are clear benefits of using disease-specific measures to assess HRQoL, these tools do not enable comparison with outcomes in nondermatological conditions. $^{10}$

Previously, results from the generic HRQoL instrument Short Form-36 (SF-36) demonstrated that disability levels in psoriasis patients are comparable to major medical disorders such as cancer. ${ }^{12}$ However, no literature review has used a systematic approach to compare the HRQoL of psoriasis patients based on the EuroQoL five dimensions (EQ-5D)derived $^{13}$ disutility values with that of other chronic disease sufferers.

The current study aimed to systematically review the EQ-5D values in clinically diagnosed or self-assessed psoriasis patients, and thus estimate the disutility of patients suffering from the disease, and furthermore to compare the
EQ-5D scores of psoriasis patients with those of patients with other chronic illnesses.

\section{Methods}

Two systematic literature reviews were conducted. The objective of the first literature search was to identify EQ-5D-derived utility values for psoriasis patients. The aim of the second search was to identify published systematic literature reviews, which reported utility values in other chronic diseases, beyond psoriasis. Both literature reviews were designed and presented in compliance with the Preferred Reporting Items for Systematic reviews and Meta-Analyses (PRISMA) guidelines. ${ }^{14}$ To avoid selection bias, the specific chronic diseases were not predetermined, and the list of chronic diseases reviewed was based on the results of the broad literature search.

\section{Use of the EQ-5D}

The EQ-5D is a nonspecific, self-reported instrument used as a measure of health outcomes or general health status validated for use across a wide range of health conditions. The tool covers five dimensions of the responder's perceived problems: mobility; self-care; usual activities; pain/discomfort; and anxiety/ depression. For each dimension, the patient selects one of five descriptors that best describes the extent of their problems (eg, "I have no problems in walking about" to "I am unable to walk about"). The descriptors are converted into numerical values, resulting in a distinct five-digit health profile for the patient (eg, 12113), indicating the relative impact of each dimension on their HRQoL. Each health profile is associated with a single utility index value ranging between 0 and 1 (where $0=$ dead and $1=$ full health) based on a weighted value set derived from previous studies. The EQ-5D also includes a Visual Analog Scale (VAS), on which respondents indicate their general state of health on a scale from 0 to 100 , where $0=$ worst health imaginable and $100=$ best health imaginable. By assessing the five aspects of HRQoL, the individually weighted EQ-5D domain scores provide a single overall utility index value that is nondisease-specific. This enables the comparison of the HRQoL impact of psoriasis with that of other chronic diseases, allowing for informed decisions to be made on resource allocation to ensure both value for money and the improvement of patient outcomes.

\section{Eligibility criteria and search terms}

To be included in the first literature review (psoriasis), studies were required to report EQ-5D-derived utility index scores at baseline. Studies that only reported EQ-5D graphically or as a percentage change over time, or those that did not report EQ-5D scores separately for the psoriasis population were 
excluded. Studies were excluded where patients were known to have psoriasis-related comorbidities. Only full-length publications reporting the results of original research in English language were included. The search terms used were (EQ5D OR EQ 5D OR EuroQoL) AND (psoria*).

The second literature review (in other disease areas) included only systematic literature reviews that reported EQ-5D utility index scores. Studies that did not specify EQ-5D-derived utility values were excluded. Reviews that did not report directly on primary publications were excluded (eg, reviews on cost utility studies). Publications on the validity of patient-reported outcomes and discussion papers on general HRQoL in various disease areas were also excluded. Only results with full-length articles available in the English language were reviewed. The search terms used were (EQ5D OR EQ 5D OR EuroQoL) AND (systematic review).

\section{Information sources}

Searches were conducted in the following databases: Embase, MEDLINE, the Cochrane Central Register of Controlled Trials (CENTRAL), BIOSIS Previews, International
Pharmaceutical Abstracts (IPAB), PASCAL, SciSearch, Econlit, EuroQoL, and the National Health Service Economic Evaluation Database (NHS EED). The first search (psoriasis) was conducted in December 2013. The second search (other chronic diseases) was conducted in March 2014. Searches were not limited by year of publication.

\section{Study selection}

Titles were screened against the inclusion criteria by two independent reviewers. Subsequent screening (of abstracts and full-text articles) involved four independent reviewers. Disagreement between reviewers at any stage was discussed and resolved by consensus opinion.

\section{Data collection}

Results were captured in a data extraction table. For studies on psoriasis (Table 1), the mean EQ-5D index scores and VAS scores were organized according to study. Where two VAS scores were reported for one study (ie, one for moderate psoriasis and one for severe psoriasis), both scores were extracted and reported.

Table I Key features of the studies included in the literature review of disutility in psoriasis patients

\begin{tabular}{|c|c|c|c|c|c|c|c|}
\hline \multirow[t]{2}{*}{ Study (location) } & \multirow[t]{2}{*}{ Study type } & \multirow{2}{*}{$\begin{array}{l}\text { Patients } \\
\text { (n) }\end{array}$} & \multirow[t]{2}{*}{ Mean age } & \multirow{2}{*}{$\begin{array}{l}\text { Disease } \\
\text { severity }\end{array}$} & \multirow[t]{2}{*}{ Active treatment } & \multicolumn{2}{|c|}{ Mean EQ-5D score } \\
\hline & & & & & & Utility index & VAS \\
\hline $\begin{array}{l}\text { Christophers et al }{ }^{15} \\
\text { (United Kingdom, } \\
\text { Italy, France, Spain, } \\
\text { Germany) }\end{array}$ & Cross-sectional & $\mathrm{I}, 434$ & 45.6 & $\begin{array}{l}\text { Mild-moderate- } \\
\text { severe }\end{array}$ & None & 0.82 & NR \\
\hline $\begin{array}{l}\text { Dauden et al }{ }^{16} \\
\text { (Europe) }^{\mathrm{a}}\end{array}$ & $\mathrm{RCT}$ & $352 / 359$ & 45 & Moderate-severe & $\begin{array}{l}\text { Etanercept (continuous } \\
\text { versus paused treatment) }\end{array}$ & 0.65 & $\begin{array}{l}60.7 \text { (severe), } \\
60.9 \text { (moderate) }\end{array}$ \\
\hline Kalb et $\mathrm{al}^{\mathrm{a}, 17}$ & Prospective & 215 & 44.4 & Moderate-severe & Infliximab & 0.78 & 73.9 \\
\hline Kulkarni et al ${ }^{18}$ (US) & Cross-sectional & $1,100,000$ & NR & NR & None & 0.59 & 59.1 \\
\hline $\begin{array}{l}\text { Norlin et al }{ }^{19} \\
\text { (Sweden) }\end{array}$ & Retrospective & 2,450 & 54 (median) & Moderate-severe & $\begin{array}{l}\text { No active treatment actively } \\
\text { prescribed or required } \\
\text { for the study; patients } \\
\text { included in the registry were } \\
\text { receiving systemic treatment } \\
\text { (no further details provided) }\end{array}$ & 0.76 & NR \\
\hline $\begin{array}{l}\text { Norlin et } \mathrm{al}^{20} \\
\text { (Sweden) }\end{array}$ & Retrospective & 267 & 48 & Moderate-severe & $\begin{array}{l}\text { Adalimumab, etanercept, } \\
\text { infliximab, ustekinumab }\end{array}$ & 0.73 & NR \\
\hline $\begin{array}{l}\text { Rosen et } \mathrm{al}^{21} \\
\text { (Canada) }\end{array}$ & Case control & 201 & 46.8 & NR & None & 0.9 & NR \\
\hline $\begin{array}{l}\text { Shikiar et } \mathrm{al}^{22} \\
\text { (United States, } \\
\text { Canada) }\end{array}$ & $\mathrm{RCT}$ & 147 & 42.2 & Moderate-severe & Adalimumab & 0.66 & 72.3 \\
\hline $\begin{array}{l}\text { Shikiar et } \mathrm{al}^{23} \\
\text { (United States, } \\
\text { Canada) }\end{array}$ & $\mathrm{RCT}$ & $50 / 45 / 52$ & $44 / 46$ & Moderate-severe & $\begin{array}{l}\text { Adalimumab (weekly) } \\
\text { versus adalimumab (EOW) }\end{array}$ & 0.69 & $\begin{array}{l}70.8 \text { (severe), } \\
72.8 \text { (moderate) }\end{array}$ \\
\hline $\begin{array}{l}\text { Wade et } \mathrm{al}^{24} \\
\text { (United Kingdom) }\end{array}$ & Cross-sectional & 35 & 49.8 & Moderate-severe & Etanercept & 0.52 & 50.7 \\
\hline Weiss et $\mathrm{a}^{\mathrm{a}, 25}$ & Cross-sectional & 35 & 49 (median) & Moderate-severe & None & 0.72 & 75.1 \\
\hline Weiss et $\mathrm{al}^{\mathrm{a}, 26}$ & RCT & 32 & NR & Moderate-severe & Clobetasol & 0.78 & 67.7 \\
\hline
\end{tabular}

Note: aSpecific study countries not mentioned in the publication.

Abbreviations: n, number; EQ-5D, EuroQoL five dimensions; VAS, Visual Analog Scale; NR, not reported; RCT, randomized controlled trials; EOW, every other week. 
For systematic literature reviews of other chronic diseases, the highest and lowest reported values for the mean utility index score (at baseline) were extracted. These were referred to as the upper and lower limits for each disease. Upper and lower limits of mean VAS scores were also extracted (reported to the nearest integer). The utility values obtained from this search were used as a benchmark for comparisons with results in psoriasis patients. As confidence intervals or standard errors were not available for all papers, a meta-analysis was not conducted. Therefore, studies were not assessed for bias or quality, as this was not necessary in terms of answering the research question. However, the risk of bias was minimized by adhering to the strict methodology outlined above. Utility index scores were not modified (weighted) according to the sample size of the study from which they were extracted. The data reported are only mean index values; the ranges in our data reflect differences across different studies.

\section{Results}

\section{Study selection}

Figure 1A shows the article selection process for the systematic review of EQ-5D-derived utility values for psoriasis patients, based on the PRISMA guidelines. ${ }^{14}$ After the removal of duplicates, 133 references were identified. Follow-

A

Articles excluded in the first round on the basis of title $(n=67)$

Discussion paper $(n=1)$

Duplicate $(\mathrm{n}=10)$

Non English $(n=1)$

Not EQ-5D $(n=4)$

Not original evidence $(n=10)$

Not plaque psoriasis $(n=31)$

Not plaque psoriasis separate $(n=10)$

\section{Articles included for \\ abstract review}

$(n=66)$

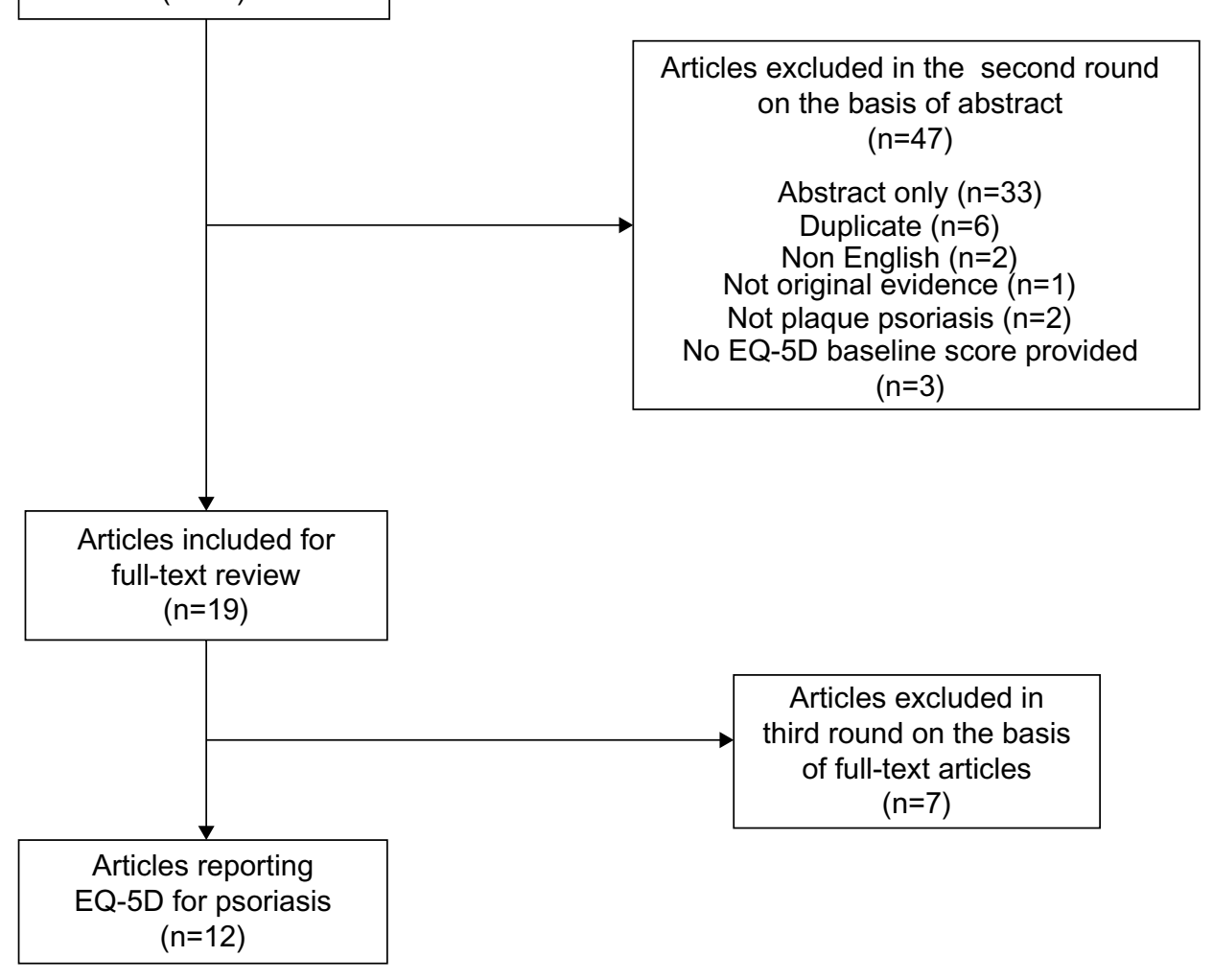

Figure I (Continued) 
B

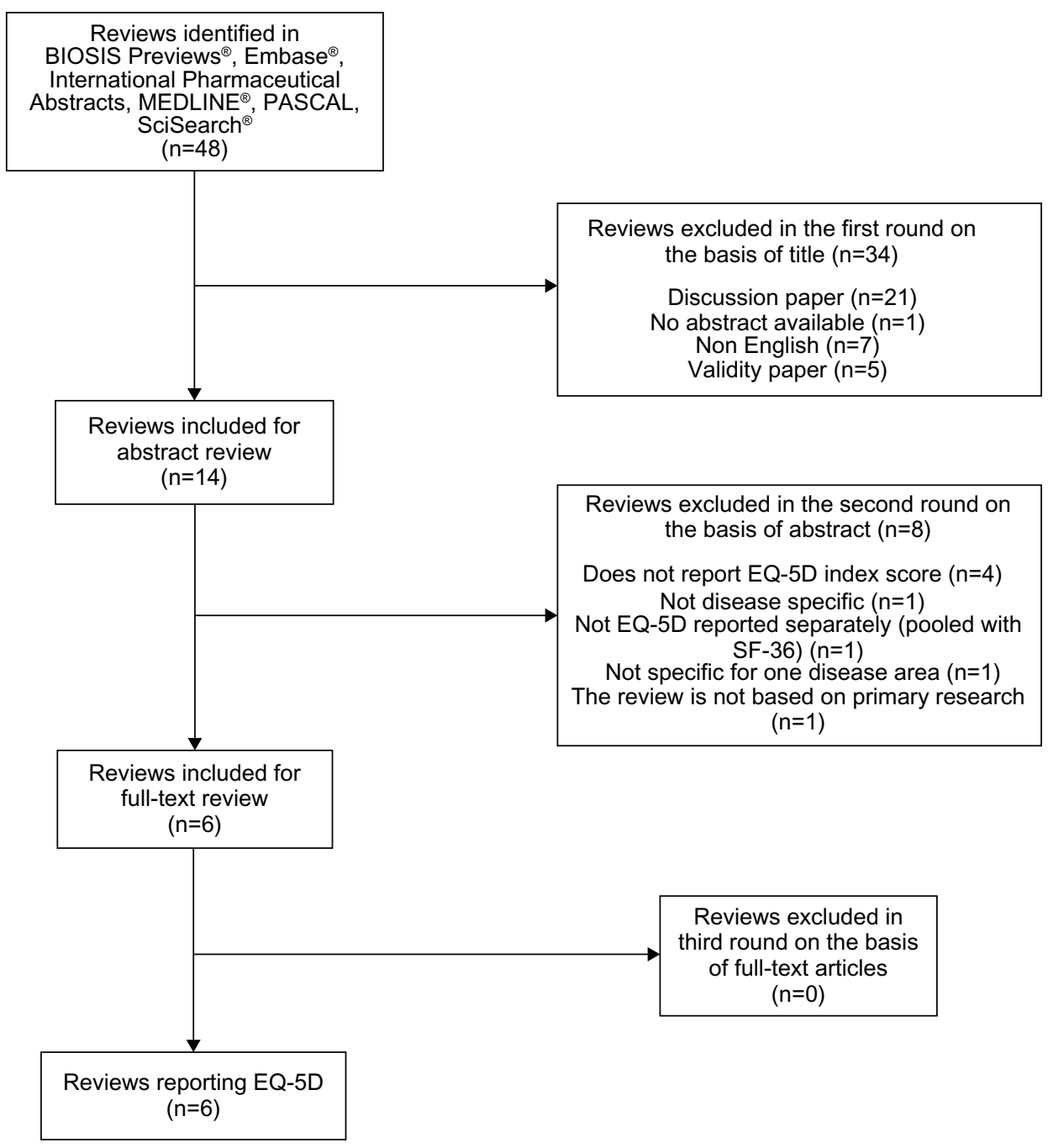

Figure I PRISMA flow charts of the selection process for including studies in the systematic reviews.

Notes: (A) Studies reporting EQ-5D scores for psoriasis patients. (B) Studies reporting EQ-5D scores for other chronic diseases (not including psoriasis).

Abbreviations: n, number; EQ-5D, EuroQoL five dimensions; SF-36, Short Form-36; PRISMA, Preferred Reporting Items for Systematic reviews and Meta-Analyses.

ing a screen of titles, 67 articles were excluded. The abstract screening process excluded a further 47 . The remaining 19 were reviewed as full-text articles, and a further seven were excluded due to nonreporting baseline EQ-5D utility index scores. A total of 12 articles were available for inclusion in the final review. ${ }^{15-26}$

Figure 1B shows the article selection process for the second systematic review of systematic literature reviews with utility values in other chronic diseases. This search identified 48 results, 34 of which were excluded on the basis of title. A further eight articles were excluded following abstract screening, leaving six systematic literature reviews for inclusion in the final review. ${ }^{27-32}$

Each of the included systematic literature reviews employed a similar methodology to the psoriasis literature review, both in terms of search strategy and data extraction. Papers were only included if they reported EQ-5D results from primary data sources in a predefined type of disease, were published in English, and had clearly defined inclusion criteria and methodology. Therefore, the outcomes extracted from both the first and second systematic literature reviews were comparable. Neither of the searches were limited by year of publication (Table 2).

\section{Study characteristics}

The 12 articles selected from the literature search on psoriasis reported data from three randomized controlled trials (RCTs), four cross-sectional studies, two retrospective studies, one prospective study, and one case-control study (Table 1). ${ }^{15-26}$ 
Table 2 Key features of the studies included in the literature review of disutility in patients with chronic diseases (not including psoriasis)

\begin{tabular}{|c|c|c|c|c|c|}
\hline Review & $\begin{array}{l}\text { Number } \\
\text { of studies }\end{array}$ & Disease & Diseases included & Time frame & Inclusion criteria \\
\hline $\begin{array}{l}\text { Dyer } \\
\text { et } \mathrm{al}^{27}\end{array}$ & 66 & $\begin{array}{l}\text { Cardiovascular } \\
\text { diseases }\end{array}$ & $\begin{array}{l}\text { Cardiovascular diseases defined } \\
\text { according to NYHA or CCS } \\
\text { classification scales (ie, heart } \\
\text { failure or angina). Severity ranges } \\
\text { from class I (mild symptoms) to } \\
\text { class IV (severe symptoms) }\end{array}$ & $\begin{array}{l}\text { January 1988- } \\
\text { October } 2008\end{array}$ & $\begin{aligned} \text { - } & \text { Original research } \\
\text { - } & \text { Reported EQ-5D specific to cardiovascular } \\
& \text { disease OR } \\
\text { - } & \text { Reported psychometric properties of } \\
& \text { EQ-5D }\end{aligned}$ \\
\hline $\begin{array}{l}\text { Janssen } \\
\text { et } \mathrm{al}^{28}\end{array}$ & 59 & $\begin{array}{l}\text { Type } 2 \\
\text { diabetes } \\
\text { mellitus }\end{array}$ & Type 2 diabetes mellitus & $1987-2009$ & $\begin{array}{l}\text { - Original research } \\
\text { - Reported EQ-5D results and/or } \\
\text { measurement properties included }\end{array}$ \\
\hline $\begin{array}{l}\text { Liem } \\
\text { et } \mathrm{al}^{29}\end{array}$ & 27 & $\begin{array}{l}\text { End-stage } \\
\text { renal diseases }\end{array}$ & $\begin{array}{l}\text { Hemodialysis, peritoneal dialysis, } \\
\text { renal transplantation }\end{array}$ & $\begin{array}{l}\text { Before } \\
\text { September } 2006\end{array}$ & $\begin{array}{l}\text { - English articles from peer-reviewed } \\
\text { journals } \\
\text { - Reported absolute utilities using VAS, } \\
\text { TTO, or SG method or utilities derived } \\
\text { from the EQ-5D or HUI questionnaires } \\
\text { - At least one of the forms of the included } \\
\text { diseases } \\
\text { - Data collected prospectively } \\
\text { - Minimum of ten patients per treatment } \\
\text { group }\end{array}$ \\
\hline $\begin{array}{l}\text { McLernon } \\
\text { et } \mathrm{al}^{30}\end{array}$ & 30 & Liver diseases & $\begin{array}{l}\text { Hepatitis A/B/C, cirrhosis, chronic } \\
\text { liver disease, hepatocellular } \\
\text { carcinoma, liver metastasis, } \\
\text { hepatic encephalopathy, } \\
\text { spontaneous bacterial peritonitis, } \\
\text { ascites, variceal hemorrhage, liver } \\
\text { transplant }\end{array}$ & $\begin{array}{l}\text { September } \\
\text { 1966-September } \\
2006\end{array}$ & $\begin{array}{l}\text { - English articles } \\
\text { - Health-state utility tools or expert opinion } \\
\quad \text { used }\end{array}$ \\
\hline $\begin{array}{l}\text { Pickard } \\
\text { et } \mathrm{al}^{31}\end{array}$ & 34 & $\begin{array}{l}\text { Cancer } \\
\text { diseases }\end{array}$ & $\begin{array}{l}\text { Breast cancer, prostate cancer, } \\
\text { cancers of the digestive system }\end{array}$ & $\begin{array}{l}\text { January 1988- } \\
\text { January } 2006\end{array}$ & $\begin{array}{l}\text { - Original research } \\
\text { - Article reported EQ-5D psychometric } \\
\text { properties or EQ-5D index, VAS, or } \\
\text { percentage dimension cores for cancer } \\
\text { patients }\end{array}$ \\
\hline $\begin{array}{l}\text { Tosh } \\
\text { et } \mathrm{al}^{32}\end{array}$ & 31 & $\begin{array}{l}\text { Visual } \\
\text { disorders }\end{array}$ & $\begin{array}{l}\text { Glaucoma, age-related macular } \\
\text { degeneration, cataracts, diabetic } \\
\text { retinopathy, conjunctivitis, other } \\
\text { visual disorders }\end{array}$ & $2001-2010$ & $\begin{array}{l}\text { - English articles } \\
\text { - At least one from EQ-5D, SF-6D, or } \\
\text { HUI-3 reported, plus another QoL } \\
\text { measure (generic or condition-specific) or } \\
\text { a measure of clinical severity }\end{array}$ \\
\hline
\end{tabular}

Abbreviations: NYHA, New York Heart Association; CCS, Canadian Cardiovascular Society; EQ-5D, EuroQoL five dimensions; VAS, Visual Analog Scale; TTO, time trade-off; SG, standard gamble; HUI, health utilities index; SF-6D, Short Form six dimensions; QoL, quality of life.

Two of these studies did not report disease severity; one reported on patients with mild, moderate, or severe psoriasis; and nine reported only on moderate-severe psoriasis. Seven of the 12 studies involved patients taking active treatments; in these cases, only the baseline scores were reported.

The six articles selected from the literature search in other chronic diseases provided EQ-5D scores for cardiovascular diseases, Type 2 diabetes mellitus, end-stage renal diseases, liver diseases (including hepatitis $\mathrm{A} / \mathrm{B} / \mathrm{C}$, ascites, and cirrhosis), cancer, and visual disorders. ${ }^{27-32}$ The number of studies included in these systematic literature reviews ranged from 27 to 66 . Key details of each article are summarized in Table 2.

\section{Results of individual studies: EQ-5D utility index scores}

The mean baseline EQ-5D utility index scores for patients with psoriasis ranged from 0.52 (standard deviation: 0.39$)^{24}$ to 0.9 (standard deviation: 0.1$)^{21}$ for all disease severities (Figure 2). The median EQ-5D index score was $0.72 .{ }^{25}$ All baseline EQ-5D scores in psoriasis patients were within the range reported for other chronic diseases (0.20-0.93).

The reported EQ-5D lower limit for all other chronic diseases ranged from 0.20 to 0.66 . The lowest utility index scores were reported in literature reviews of studies in Type 2 diabetes mellitus (0.20) and cardiovascular diseases (0.24) ${ }^{27,28}$ Of the lower estimates for all diseases, the highest 


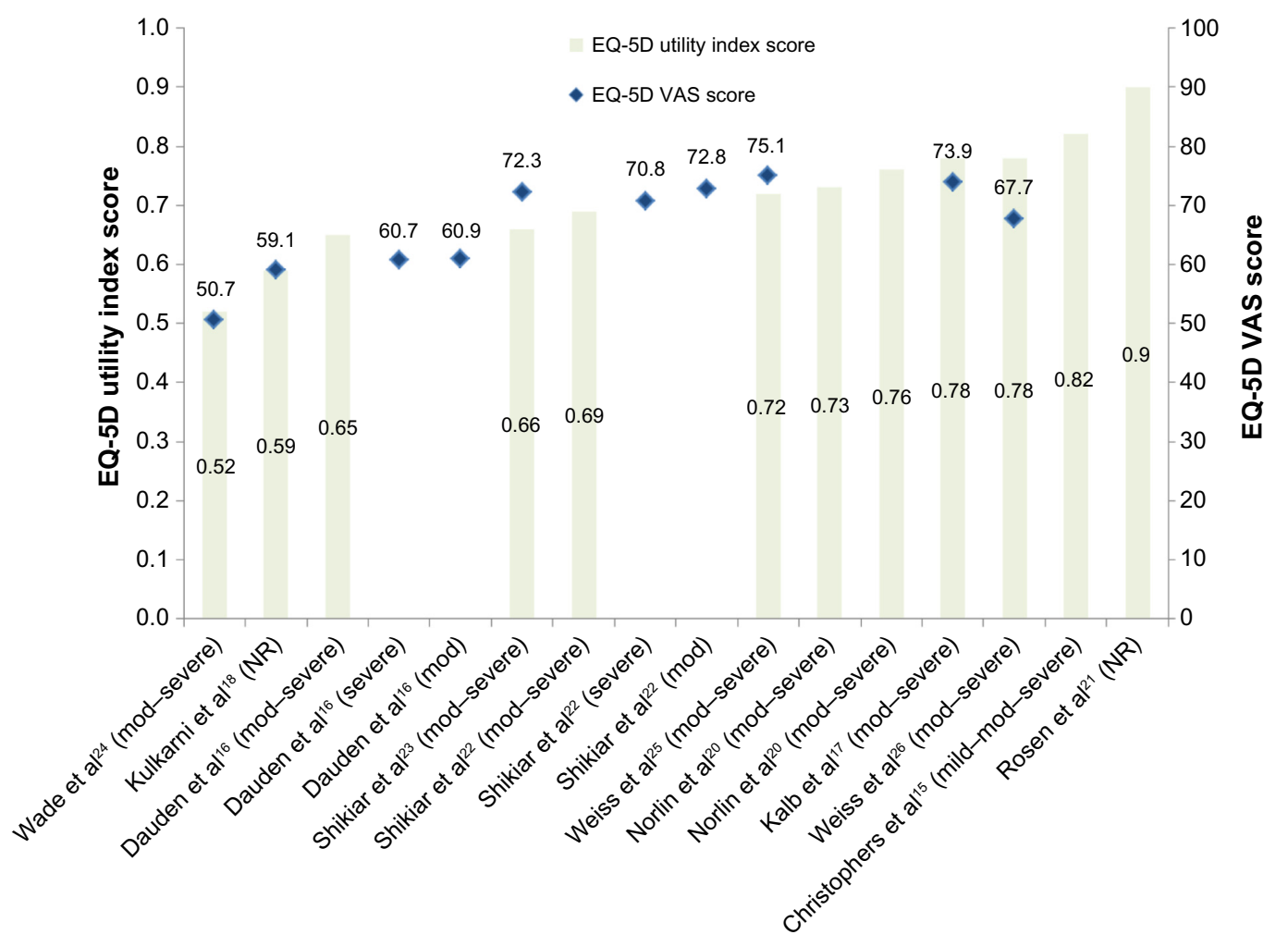

Figure 2 Mean baseline EQ-5D utility index and VAS score estimates for psoriasis patients.

Notes: Scale for utility index score: $0=$ dead; $I=$ full health. Scale for VAS score: $0=$ worst health imaginable; $100=$ best health imaginable. Rosen et al ${ }^{21}$ reported utility scores to one decimal place (all other studies reported to two decimal places).

Abbreviations: EQ-5D, EuroQoL five dimensions; VAS, Visual Analog Scale; mod, moderate; NR, not reported.

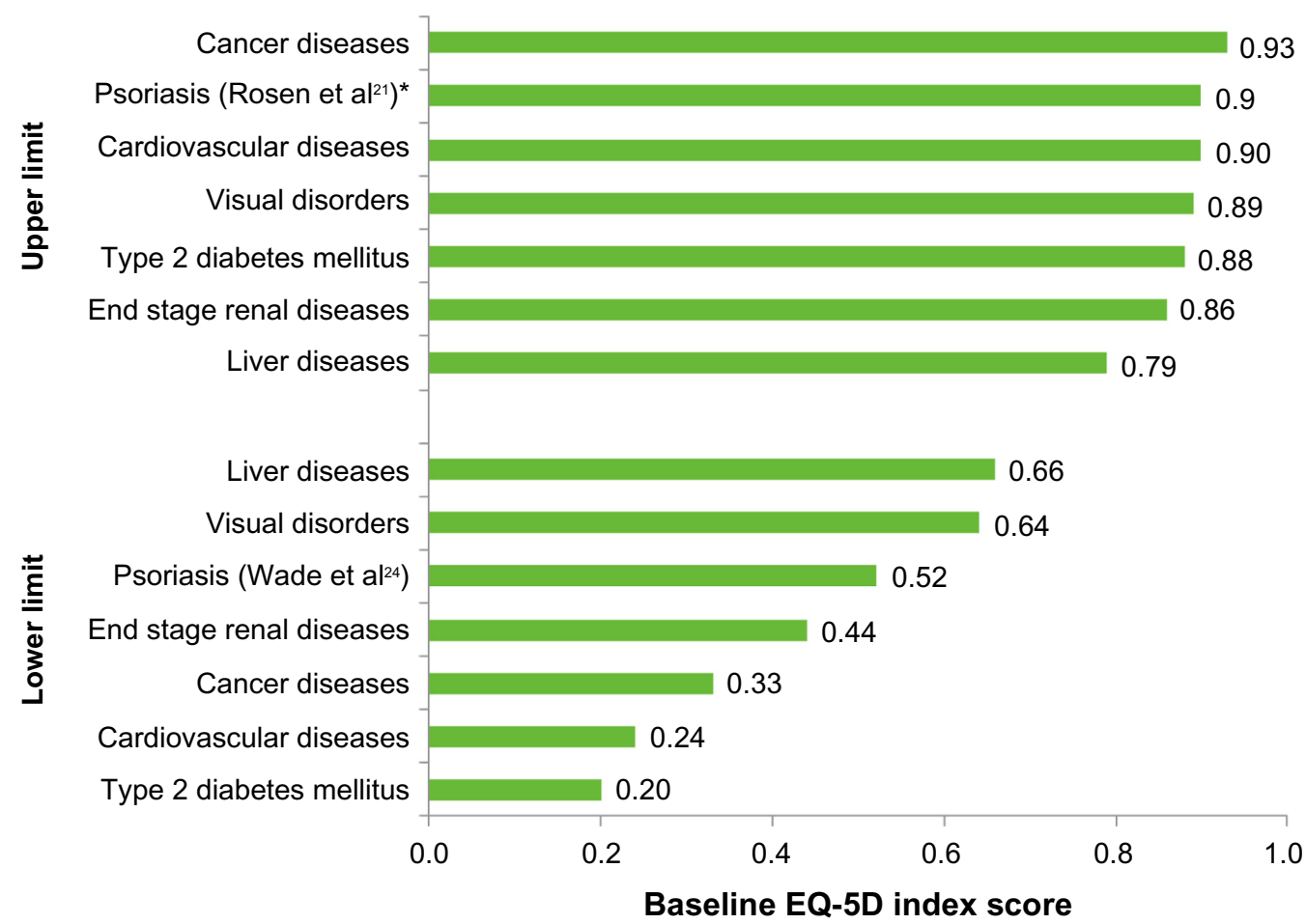

Figure 3 Upper and lower EQ-5D utility index score estimates for psoriasis and other chronic diseases.

Notes: Scale: $0=$ dead; $I=$ full health. *Rosen et al reported the utility score to one decimal place (all other studies reported to two decimal places). Rosen and Wade were included in the chart in order to distinguish them from the other psoriasis articles, highlighting that these only reflect the findings from two of the papers. Abbreviation: EQ-5D, EuroQoL five dimensions. 


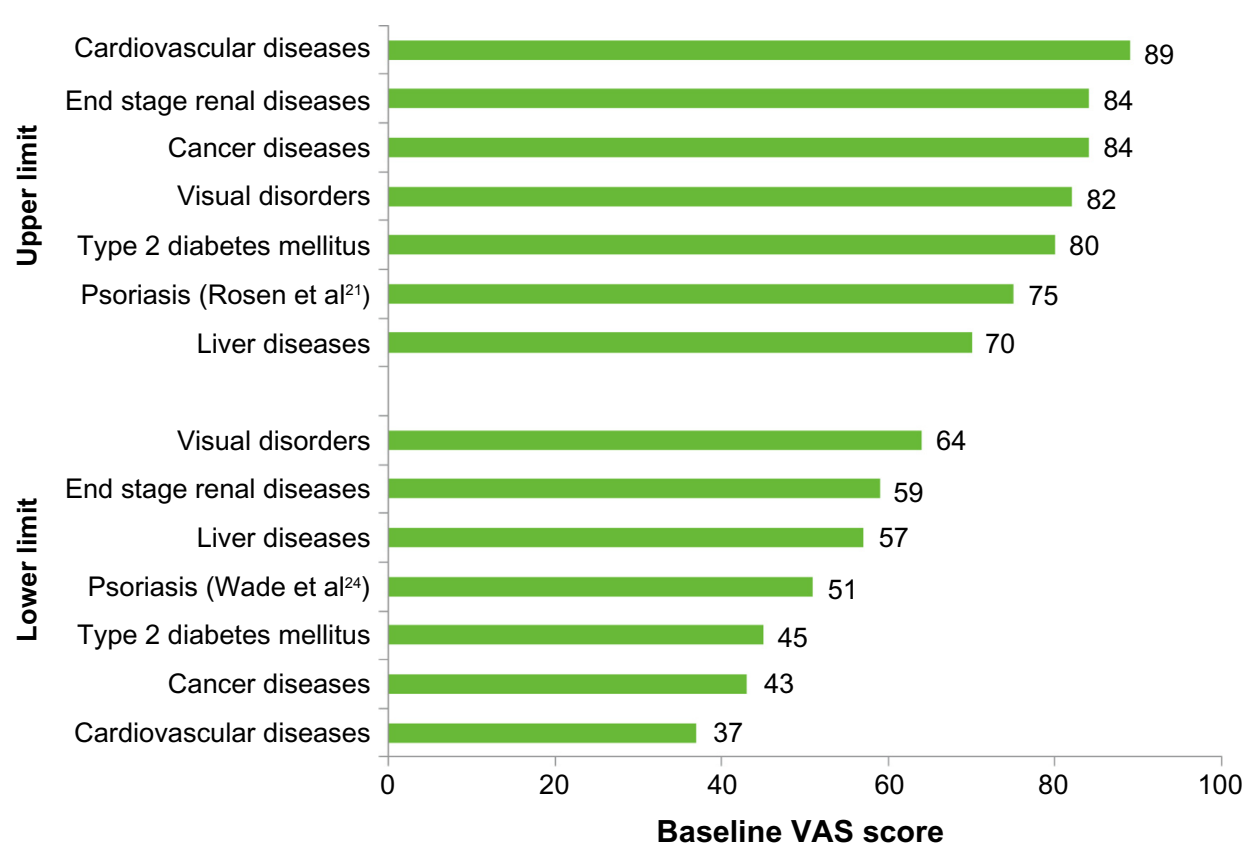

Figure 4 Upper and lower EQ-5D VAS score estimates for psoriasis and other chronic diseases.

Notes: Scale: $0=$ worst health imaginable; $100=$ best health imaginable. Rosen and Wade were included in the chart in order to distinguish them from the other psoriasis articles, highlighting that these only reflect the findings from two of the papers.

Abbreviations: VAS, Visual Analog Scale; EQ-5D, EuroQoL five dimensions.

EQ-5D-derived utility values were reported in studies of visual disorders $(0.64)$ and liver diseases $(0.66) .{ }^{30,32}$ The disutility experienced by psoriasis patients was more substantial than this: the lowest EQ-5D utility score reported for psoriasis was 0.52 (similar to end-stage renal disease, at 0.44 ).

The reported EQ-5D upper limit across other diseases ranged from 0.79 (liver disease patients) to 0.93 (cancer patients) ${ }^{30,31}$ For all diseases (with the exception of liver diseases), the EQ-5D upper limit was within \pm 0.04 of the upper estimate for psoriasis $(0.9$ [26]). For liver diseases, although the upper limit (0.79) appears considerably lower than the upper limit for psoriasis, the opposite trend was observed in the lower limits. The lowest EQ-5D estimate for psoriasis patients $(0.52)$ is 0.14 , lower than that for liver disease patients $(0.66){ }^{30}$

The upper and lower limits for EQ-5D index scores across all diseases (including psoriasis) are presented in Figure 3.

\section{Results of individual studies: EQ-5DVAS scores}

The EQ-5D VAS scores for patients with psoriasis ranged from 50.7 to 75.1 (Figure 2) with a median VAS score of 65.1 across all psoriasis studies. This was within the range reported for other chronic diseases - ie, 37-89.

The VAS lower limit reported for other chronic diseases ranged from 37 (cardiovascular diseases) to 64 (visual disorders). ${ }^{27,32}$ The lower limit reported for patients with psoriasis (50.7) was lower than that for patients with liver diseases, end-stage renal diseases, and visual disorders.

The range in the VAS upper limit for other chronic diseases was 70-89. Only the literature review on liver diseases reported an upper limit below that reported in psoriasis studies (liver disease upper limit: 60; psoriasis upper limit: 75.1). ${ }^{25,30}$

The upper and lower limits for EQ-5D VAS scores across all diseases (including psoriasis) are presented in Figure 4.

\section{Conclusion}

This is the first systematic literature review to use the EQ-5D to compare the disutility in psoriasis patients with that of other chronic diseases. Consistent with previous estimates using the SF-36, ${ }^{12}$ our results confirm and emphasize the significant disutility associated with psoriasis. Psoriasis patients suffer from the same deterioration in HRQoL as patients with other serious chronic diseases including cancer and cardiovascular diseases. In some cases, the disutility in psoriasis patients is more severe. The results indicate that psoriasis has a significant physical, social, and psychological impact, and is therefore a must-treat disease.

Limitations of this systematic review should be considered. No quality assessment was conducted. The absence of confidence intervals and standard errors in many studies did not allow for a meta-analysis of the data. Furthermore, there was no clear reporting of disease 
severity or other baseline characteristics, thereby prohibiting the assessment of or adjustment for bias or heterogeneity. This introduces limitations associated with qualitative comparisons. Where possible, articles were excluded if they reported on patients with psoriatic arthritis, but not all studies explicitly described such comorbidities within the inclusion or exclusion criteria. It is therefore possible that comorbidities such as psoriatic arthritis may have influenced the lower mean EQ-5D scores reported in those studies. The severity of psoriasis varied across the studies identified, and in two cases, severity was not reported at all. ${ }^{18,21}$ Of the psoriasis studies that reported disease severity, one study reported EQ-5D scores across a population with either mild, moderate, or severe psoriasis,${ }^{15}$ while nine studies reported only on moderate-severe psoriasis. . $^{16,17,19,20,22-26}$ This may explain the large range between upper and lower utility estimates. Study design also varied - some papers reported retrospective or cross-sectional data, while others contained data from RCTs. It is possible that patients included in the RCTs were more likely to be suffering from a flare of psoriasis, as active disease is often an inclusion criterion for interventional studies. However, upon reviewing the data, we found no patterns or bias in the utility values of psoriasis patients according to study type.

Utility index scores were not modified (weighted) according to the sample size of the study. If study results had not been equally weighted, a different range of disutility for psoriasis may have been observed. For example, weighting the results would give more significance to one of the lowest utility index scores reported (0.59), deduced from a study population of 1.1 million patients. ${ }^{18}$

The calculations used to derive EQ-5D scores in the literature identified are based on country-specific datasets, so scores may differ according to the valuation used. As the psoriasis studies did not explicitly describe the EQ-5D calculations employed, the possibility of minor score variations between countries cannot be ruled out. Where mentioned, study locations have been included in Table 1 .

Another important limitation of our review is that the psoriasis studies identified only reported the overall index utility values and VAS scores (ie, not the individual scores for the five domains of the EQ-5D - mobility, self-care, usual activities, pain/discomfort, and anxiety/depression). This prevents identification of any specific drivers of disutility in psoriasis patients. A previous study using the SF-36 identified physical, psychological, and social factors as contributors to the disutility associated with psoriasis. $^{12}$
Although the EQ-5D has been extensively used in a wide range of diseases, only six systematic literature reviews met the inclusion criteria for the second (nonpsoriasis) literature search. However, the six included systematic reviews each included at least 27 primary research studies (and in one case, 66 primary research studies). ${ }^{27}$ This therefore suggests that the findings of the literature reviews are balanced between psoriasis studies and nonpsoriasis studies, and the qualitative comparison of EQ-5D scores between the two systematic reviews provides a good indication of the disutility associated with psoriasis compared to the chronic diseases reviewed (cardiovascular diseases, diabetes, end-stage renal diseases, liver diseases, cancer, and visual disorders). Further research to compare disutility in psoriasis with other chronic diseases is needed.

Given the substantial psychological impact of psoriasis, it is expected that anxiety/depression would be a greater driver of disutility than some other domains. Many chronic diseases are linked to depression (including cancer, diabetes, and heart disease), ${ }^{33}$ but chronic dermatological diseases carry an additional burden due to the social stigma associated with skin abnormalities, which can lead to depression and other psychological issues. ${ }^{7}$ It has previously been suggested that $90 \%$ of psoriasis patients have feelings of stigmatization due to their condition. ${ }^{7}$ It is this social stigma that is thought to exacerbate the depression experienced by psoriasis patients, differentiating them from patients with other chronic diseases. The prominence of psychological issues in psoriasis was supported by one of the studies initially identified in this review. ${ }^{34}$ Although scores were not reported for the individual EQ-5D domains, the study reported that $53 \%$ of psoriasis patients reported problems in the anxiety/depression dimension of EQ-5D. ${ }^{34}$ This figure was higher than had previously been reported for patients with asthma, cancer, chronic obstructive pulmonary disease, heart disease, and diabetes (exact percentages not reported)..$^{34}$

Further research is therefore warranted to better understand the drivers of reduced HRQoL in psoriasis patients. This could include the use of the disease-specific version of the EQ-5D for psoriasis (EQ-5D-5L-PSO) as a bolt-on instrument, which allows further exploration into the different dimensions of HRQoL. ${ }^{35}$ The EQ-5D-5L-PSO covers skin irritation, appearance, self-confidence and social/relationship difficulties, in addition to the original five dimensions of the EQ-5D. As a more specific tool, this could also be used to investigate the differences in HRQoL between mild, moderate, and severe psoriasis patients. 


\section{Acknowledgments}

This study was funded by Leo Pharma. Editorial support was provided by Adelphi Values.

\section{Disclosure}

Anders Holmen Møller and Sandra Erntoft are employed by LEO Pharma A/S. Gregor BE Jemec has had the following affiliations or financial interests: Advisory Board/Panel for AbbVie, AstraZeneca, Janssen-Cilag, MSD, Novartis and Pfizer; consultant for AbbVie, AstraZeneca and Novartis; grants/research support from AbbVie and LEO Pharma A/S; speaker's bureau at AbbVie; stock/shareholder in Novo and Alk-Albello. Gabrielle R Vinding has no relevant conflicts of interest.

\section{References}

1. Parisi R, Symmons DPM, Griffiths CEM, Ashcroft DM. Global epidemiology of psoriasis: a systematic review of incidence and prevalence. J Invest Dermatol. 2012;133(2):377-385.

2. Yeung H, Takeshita J, Mehta NN, et al. Psoriasis severity and the prevalence of major medical comorbidity: a population-based study. JAMA Dermatol. 2013;149(10):1173-1179.

3. The Lewin Group, Inc. The Burden of Skin Diseases 2005. Cleveland, OH: The Society for Investigative Dermatology; 2005. Available from: http://www.lewin.com/ /media/Lewin/Site_Sections/Publications/ april2005skindisease.pdf. Accessed April 16, 2014.

4. Griffiths CE, Barker JN. Pathogenesis and clinical features of psoriasis. Lancet. 2007;370(9583):263-271.

5. Tan X, Feldman SR, Balkrishnan R. Quality of life issues and measurement in patients with psoriasis. Psoriasis: Targets and Therapy. 2012;2012(2):13-23.

6. Miller IM, Ellervik C, Yazdanyar S, Jemec GB. Meta-analysis of psoriasis, cardiovascular disease, and associated risk factors. $J$ Am Acad Dermatol. 2013;69(6):1014-1024.

7. Hrehorów E, Salomon J, Matusiak L, Reich A, Szepietowski JC. Patients with psoriasis feel stigmatized. Acta Derm Venereol. 2012;92(1): $67-72$.

8. Anstey A, McAteer H, Kamath N, Percival F. Extending psychosocial assessment of patients with psoriasis in the UK, using a self-rateds, web-based survey. Clin Exp Dermatol. 2012;37(7):735-740.

9. Evers AW, Lu Y, Duller P, van der Valk PG, Kraaimaat FW, van de Kerkhof PC. Common burden of chronic skin diseases? Contributors to psychological distress in adults with psoriasis and atopic dermatitis. Br J Dermatol. 2005;152(6):1275-1281.

10. Bhosle MJ, Kulkarni A, Feldman SR, Balkrishnan R. Quality of life in patients with psoriasis. Health Qual Life Outcomes. 2006(4):35-37.

11. Jemec GB, Wulf HC. Patient-physician consensus on quality of life in dermatology. Clin Exp Dermatol. 1996;21(3):177-179.

12. Rapp SR, Feldman SR, Exum ML, Fleischer AB, Reboussin DM. Psoriasis causes as much disability as other major medical diseases. J Am Acad Dermatol. 1999;41(3 Pt 1):401-407.

13. Brooks R. EuroQol: the current state of play. Health Policy. 1996;37(1): 53-72.

14. Moher D, Liberati A, Tetzlaff J, Altman DG; PRISMA Group. Preferred reporting items for systematic reviews and meta-analyses: the PRISMA statement. J Clin Epidemiol. 2009;62(10):1006-1012.

15. Christophers E, Barker JN, Griffiths CE, et al. The risk of psoriatic arthritis remains constant following initial diagnosis of psoriasis among patients seen in European dermatology clinics. J Eur Acad Dermatol Venereol. 2010;24(5):548-554.
16. Daudén E, Griffiths CE, Ortonne JP, et al. Improvements in patientreported outcomes in moderate-to-severe psoriasis patients receiving continuous or paused etanercept treatment over 54 weeks: the CRYSTEL study. J Eur Acad Dermatol Venereol. 2009;23(12):1374-1382.

17. Kalb RE, Blauvelt A, Sofen HL, et al. Effect of infliximab on healthrelated quality of life and disease activity by body region in patients with moderate-to-severe psoriasis and inadequate response to etanercept: results from the PSUNRISE trial. J Drugs Dermatol. 2013;12(8): 874-880.

18. Kulkarni AS, Balkrishnan R, Richmond D, Pearce DJ, Feldman SR. Medication-related factors affecting health care outcomes and costs for patients with psoriasis in the United States. J Am Acad Dermatol. 2005;52(1):27-31.

19. Norlin JM, Steen Carlsson K, Persson U, Schmitt-Egenolf M. Switch to biological agent in psoriasis significantly improved clinical and patientreported outcomes in real-world practice. Dermatology. 2012;225(4): 326-332.

20. Norlin JM, Steen Carlsson K, Persson U, Schmitt-Egenolf M. Analysis of three outcome measures in moderate to severe psoriasis: a registrybased study of 2450 patients. Br J Dermatol. 2012;166(4):797-802.

21. Rosen CF, MussaniF, Chandran V,Eder L, Thavaneswaran A, Gladman DD. Patients with psoriatic arthritis have worse quality of life than those with psoriasis alone. Rheumatology (Oxford). 2012;51(3):571-576.

22. Shikiar R, Willian MK, Okun MM, Thompson CS, Revicki DA. The validity and responsiveness of three quality of life measures in the assessment of psoriasis patients: results of a phase II study. Health Qual Life Outcomes. 2006;4:71.

23. ShikiarR, Heffernan M, Langley RG, Willian MK, Okun MM, Revicki DA. Adalimumab treatment is associated with improvement in health-related quality of life in psoriasis: patient-reported outcomes from a phase II randomized controlled trial. J Dermatolog Treat. 2007;18(1):25-31.

24. Wade AG, Crawford GM, Pumford N, Koscielny V, Maycock S, McConnachie A. Baseline characteristics and patient reported outcome data of patients prescribed etanercept: web-based and telephone evaluation. BMC Med Res Methodol. 2011;11:91.

25. Weiss SC, Kimball AB, Liewehr DJ, Blauvelt A, Turner ML, Emanuel EJ. Quantifying the harmful effect of psoriasis on health-related quality of life. J Am Acad Dermatol. 2002;47(4):512-518.

26. Weiss SC, Rehmus W, Kimball AB. An assessment of the cost-utility of therapy for psoriasis. Ther Clin Risk Manag. 2006;2(3):325-328.

27. Dyer MT, Goldsmith KA, Sharples LS, Buxton MJ. A review of health utilities using the EQ-5D in studies of cardiovascular disease. Health Qual Life Outcomes. 2010;8:13.

28. Janssen MF, Lubetkin EI, Sekhobo JP, Pickard AS. The use of the EQ-5D preference-based health status measure in adults with Type 2 diabetes mellitus. Diabet Med. 2011;28(4):395-413.

29. Liem YS, Bosch JL, Hunink MG. Preference-based quality of life of patients on renal replacement therapy: a systematic review and metaanalysis. Value Health. 2008;11(4):733-741.

30. McLernon DJ, Dillon J, Donnan PT. Health-state utilities in liver disease: a systematic review. Med Decis Making. 2008;28(4):582-592.

31. Pickard AS, Wilke CT, Lin HW, Lloyd A. Health utilities using the EQ-5D in studies of cancer. Pharmacoeconomics. 2007;25(5):365-384.

32. Tosh J, Brazier J, Evans P, Longworth L. A review of generic preference-based measures of health-related quality of life in visual disorders. Value Health. 2012;15(1):118-127.

33. National Institute of Mental Health [webpage on the Internet]. What is depression? Bethesda, MD: National Institute of Mental Health; 2011. Available from: http://www.nimh.nih.gov/health/publications/ depression/index.shtml\#pub4. Accessed May 13, 2014.

34. Reich K, Segaert S, Van de Kerkhof P, et al. Once-weekly administration of etanercept $50 \mathrm{mg}$ improves patient-reported outcomes in patients with moderate-to-severe plaque psoriasis. Dermatology. 2009;219(3): 239-249.

35. Swinburn P, Lloyd A, Boye KS, Edson-Heredia E, Bowman L, Janssen B. Development of a disease-specific version of the EQ-5D-5L for use in patients suffering from psoriasis: lessons learned from a feasibility study in the UK. Value Health. 2013;16(8):1156-1162. 
Patient Related Outcome Measures

Dovepress

\section{Publish your work in this journal}

Patient Related Outcome Measures is an international, peer-reviewed, open access journal focusing on treatment outcomes specifically relevant to patients. All aspects of patient care are addressed within the journal and practitioners from all disciplines are invited to submit their work as well as healthcare researchers and patient support groups.

Submit your manuscript here: http://www.dovepress.com/patient-related-outcome-measures-journal
The manuscript management system is completely online and includes a very quick and fair peer-review system. Visit http://www.dovepress. com/testimonials.php to read real quotes from published authors. 